\title{
THE EPILEPTIC THRESHOLD IN SCHIZOPHRENIA
}

\author{
BY
}

\section{J. HOENIG and D. M. LEIBERMAN}

\author{
From the Bethlem Royal Hospital and the Maudsley Hospital, London
}

From time to time in the history of psychiatry attention has been centred on the relationship between epilepsy and schizophrenia. The views held on this subject seem to have moved through three distinct phases, like a Hegelian dialectical triad of thesis, antithesis, and synthesis. The first phase was characterized by a purely descriptive approach. Kraepelin (1910) noticed the occurrence of epileptic phenomena in $18 \%$ of his schizophrenics. Other observers have recorded figures of from $0.33 \%$ (Strauss) to $8.6 \%$ (Giese). In the absence of agreement about the incidence of these phenomena, the existence of the two conditions in one patient was presumed to be coincidental.

The second phase is best illustrated by the writings of Müller (1930) and Krapf (1929), who doubted whether the phenomena observed by the previous authors were due to idiopathic epilepsy and showed that cases reported as such in the literature were probably symptomatic epilepsies due to some coincidental pathology. They believed that a "relationship" of mutual exclusiveness existed, the constitutional basis of the two disorders being at opposite poles. A modification of this view led Meduna (1937) to try the induction of fits in the treatment of schizophrenia : he had noticed the remission that often occurred after spontaneous fits. While Meduna's trials led to one of the most spectacular advances in psychiatric therapy, the fact that the treatment proved far more valuable in conditions other than schizophrenia allowed the discussion of "schizophrenia and epilepsy" to recede into the background.

The third phase came with the advance of diagnostic methods in relation to epilepsy, and particularly with the introduction of the electroencephalogram (E.E.G.). The literature of this epoch was summarized by Hill (1948) who himself contributed important observations. Some writers, for example Hoch (1943), upheld the original Kraepelinian view of " total independence" ; Hoch did not publish any electroencephalographic studies of his own, but arrived at his conclusions by analysing reports in the literature. Others, notably Jasper, Fitzpatrick, and Solomon (1939), Gibbs, Gibbs, and Lennox (1938), and Davis (1940), found that epileptic types of electroencephalographic changes were more common in schizophrenia than chance would lead one to expect, and came to the conclusion that a chance relationship could not account for the occurrence of epileptic fits in schizophrenia. These workers believe that there is a positive relationship between the conditions of epilepsy and schizophrenia ; its exact nature is as yet incompletely understood, and observations so far made invite further investigations.

The use of the E.E.G. made the diagnosis of epilepsy more precise in certain ways ; for example, by the localization of discharging foci and the recognition of epileptic patterns in the periods between fits. It showed that when normal individuals are convulsed the electrical brain patterns are in no way different from those of epileptics with similar convulsions. That is to say, the tendency to epileptic discharges or to epileptic dysrhythmia is a property, under certain conditions, of all types of brain.

It has become common practice to study the E.E.G. under conditions of physiological change produced by over-breathing, lowering the blood sugar level either by starvation or insulin injection, the use of convulsants, the action of flickering light on the retina, etc. All these methods give a measurement of the stimulus required to make the brain discharge in an epileptic fashion. This is called the "threshold value" and can be stated in terms of the particular stimulus required in a particular individual to provoke an epileptic change in the E.E.G. A low threshold is considered to indicate a tendency to convulse easily.

These new methods change the whole question, for the main problem no longer depends on the association between schizophrenia and fits, but rather on whether there are in epilepsy and schizophrenia either some common or some mutually antagonistic neurophysiological mechanisms. This 
in turn merges into the wider problem of the somatic changes in schizophrenia.

We are reporting elsewhere (Leiberman and Hoenig, 1953 ; Leiberman, Hoenig, and Hacker, 1953) a study of schizophrenics and epileptics, using the concept of the metrazol-flicker-threshold developed by Gastaut and Hunter (1950). The present investigation arose from observation of patients undergoing insulin coma therapy. We became aware of the frequent occurrence of muscular twitching, myoclonic jerking, and actual convulsions, which are now all recognized as the clinical accompaniments of "epileptic" discharges in the E.E.G., and it appeared, moreover, that the patients who regularly showed these phenomena recovered more frequently than those who did not. In a sense, the insulin was being used as a provocative agent, though the problem was being approached in an indirect way.

\section{Material}

The patients whose case histories were studied were all in-patients in the Bethlem Royal Hospital and Maudsley Hospital, and had "deep insulin therapy " between January, 1947, and December, 1951. The total number investigated was 304, which did not include patients in whom the treatment was interrupted prematurely because of death, irreversible coma, gangrene, intercurrent illness, or a patient's refusal to continue.

According to the immediate outcome of the treatment, the patients fell into three groups : recovered, $87(28.6 \%)$; improved, $121(39.8 \%)$; and not improved, $96(31.6 \%)$.

In all these patients the diagnosis of schizophrenia had been made before treatment was started. Since not all schizophrenics are treated by deep insulin, this is only a fraction of all patients admitted to the joint hospital with a diagnosis of schizophrenia during the years under investigation.

The age of the patients ranged from 7 years to 46. By far the largest number fell between the ages of 20 and 30, the average being about 27 years. The average age in each group was nearly the same, although the range differed somewhat : recovered, $27 \cdot 3$ years, ranging from 17 to 40 ; improved, 28.2 years, ranging from 15 to 46 ; and not improved, $25 \cdot 5$ years, ranging from 7 to 46 . Details of age distribution in relation to the outcome of treatment are discussed below.

The average number of " treatment days " of the insulin coma therapy was 52.3 days for the "recovered" group, 50.8 days for the "improved" group, and 53.7 days for the "not improved" group; the differences are not significant. The average number of comas in each group was: recovered, 33.8 ; improved, 35.3 ; and not improved 33.6. Again the differences are insignificant.

\section{Methods}

The information analysed in this report was taken from case records only, the diagnosis being made always by the physician in charge of the patient and entered clearly on the front sheet of the case records. Often the diagnosis was more specific, giving the type of schizophrenia, e.g. catatonia, hebephrenia, but as this was not done in all cases no attempt has been made to keep the diagnostic subgroups separate.

On the front sheet is also entered the outcome of the treatment. From 1949 onwards this was stated under the six headings shown below, but in order to simplify we classified the outcome in three groups, namely : (I) recovered (which corresponds to 1), (II) improved (which corresponds to 2-4), and (III) not improved (which corresponds to 5-6).

\begin{tabular}{|c|c|c|c|c|c|}
\hline \multicolumn{5}{|c|}{ Original Classification in Case Records } & \multirow{2}{*}{$\begin{array}{l}\text { Our Classification } \\
\text { (I) Recovered } \\
\text { (II) Improved } \\
\text { (III) Not improved }\end{array}$} \\
\hline $\begin{array}{l}(1) \\
(2) \\
(3) \\
(4) \\
(5) \\
(6)\end{array}$ & $\begin{array}{l}\text { Recovered.. } \\
\text { Much improved } \\
\text { Improved } \\
\text { Slightly improved I } \\
\text { No change } \\
\text { Worse }\end{array}$ & $\begin{array}{l}\cdots \\
\cdots \\
\cdots\end{array}$ & .. & $\begin{array}{c}\cdots \\
\cdots\end{array}$ & \\
\hline
\end{tabular}

We further examined the records of the actual insulin treatment, which are filled in each day by the nurse who supervises the treatment, and which give a variety of information. The occurrence of epileptic phenomena, i.e. twitchings or myoclonic jerks, is recorded in a special column headed "twitches" and is indicated by one or more crosses. Epileptic fits are also recorded separately. Since this investigation was not designed as an experiment, but is katamnesic in nature, the entries by the nurses were " blind".

The investigation consisted in counting the days on which epileptic phenomena, such as " twitches", myoclonus, or fits, occurred in the course of the treatment, and expressing them in a percentage of the total number of treatment days. Thus if phenomena occurred in 10 days out of a total of 50 days the figure would be $20 \%$. Grouping the patients into the three groups of " recovered", " improved", and " not improved", the averages of these percentages in the different groups were compared.

\section{Results}

The results are tabulated in Tables I and II. The averages in Groups II and III are similar, although the "improved" group persistently shows a slightly but insignificantly higher average than the 
TABLE I

NUMBER OF DAYS ON WHICH " EPILEPTIC " PHENOMENA OCCURRED* DURING INSULIN COMA THERAPY, AS PERCENTAGES OF TOTAL NUMBER OF TREATMENT DAYS

\begin{tabular}{|c|c|c|c|c|}
\hline \multirow{2}{*}{$\begin{array}{c}\text { Treatment } \\
\text { Year }\end{array}$} & \multicolumn{3}{|c|}{$\begin{array}{l}\text { No. of Days when Epileptic } \\
\text { Phenomena Occurred }\end{array}$} & \multirow{2}{*}{$\begin{array}{l}\text { II }+ \text { III Not } \\
\text { Recovered }\end{array}$} \\
\hline & $\begin{array}{c}\text { I } \\
\text { Recovered }\end{array}$ & $\underset{\text { Improved }}{\text { II }}$ & $\underset{\substack{\text { Not } \\
\text { Improved }}}{\text { III }}$ & \\
\hline $\begin{array}{l}1947 \\
1948 \\
1949 \\
1950 \\
1951\end{array}$ & $\begin{array}{l}33 \cdot 1 \\
43.8 \\
54 \cdot 2 \\
40.9 \\
39.5\end{array}$ & $\begin{array}{l}19 \cdot 3 \\
29 \cdot 5 \\
33 \\
28 \cdot 7 \\
26 \cdot 4\end{array}$ & $\begin{array}{l}17 \cdot 1 \\
25 \cdot 1 \\
25 \cdot 3 \\
23 \cdot 3 \\
20 \cdot 4\end{array}$ & $\begin{array}{l}18 \cdot 1 \\
27.9 \\
30 \\
28 \\
23 \cdot 6\end{array}$ \\
\hline Total & $41 \cdot 17$ & $27 \cdot 83$ & 22.95 & 25.67 \\
\hline
\end{tabular}

*The figures were worked out for each patient and averaged.

TABLE II

THE INCIDENCE OF EPILEPTIFORM FITS IN THE COURSE OF TREATMENT

\begin{tabular}{l|c|c|c|c|c|c}
\hline & \multicolumn{2}{|c|}{ Recovered } & \multicolumn{2}{|c|}{ Improved } & Not Improved \\
\cline { 1 - 5 } & $\begin{array}{c}\text { Total } \\
\text { No. of } \\
\text { Patients }\end{array}$ & $\begin{array}{c}\text { No. of } \\
\text { Patients } \\
\text { with } \\
\text { Fits }\end{array}$ & $\begin{array}{c}\text { Total } \\
\text { No. of } \\
\text { Patients }\end{array}$ & $\begin{array}{c}\text { No. of } \\
\text { Patients } \\
\text { with } \\
\text { Fits }\end{array}$ & $\begin{array}{c}\text { Total } \\
\text { No. of } \\
\text { Patients }\end{array}$ & $\begin{array}{c}\text { No. of } \\
\text { Patients } \\
\text { with } \\
\text { Fits }\end{array}$ \\
\hline Total & 87 & 33 & 121 & 38 & 96 & 14 \\
\hline Percentage & $37 \cdot 9$ & $31 \cdot 4$ & $14 \cdot 6$ \\
\hline
\end{tabular}

"not-improved" group (Fig. 1). Groups II and III were therefore made into one group, the " not recovered" group; this group differs from the " recovered" group persistently year by year, and the difference is statistically significant.

Table I shows clearly that in those patients who recovered after deep insulin therapy epileptic phenomena, such as myoclonic jerks or fits, occurred more frequently than in those who did not recover.

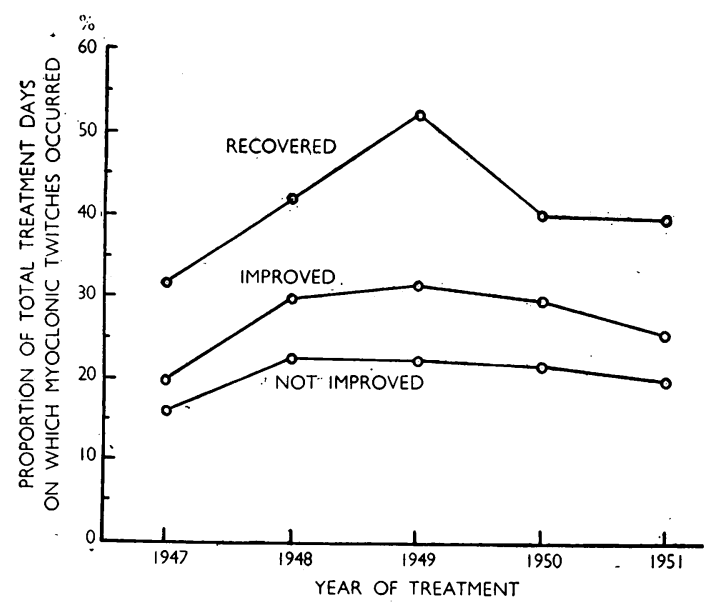

FIG. 1
Table II shows the occurrence of fits only in relation to short-term prognosis. No notice was taken of the number of fits each patient had, but only of the occurrence or absence of fits as such. The difference between the groups is again striking and on statistical examination is shown to be significant.

\section{Discussion}

There are various possible sources of error in the observations which may affect these results. In a busy insulin unit some at least of the minor manifestations of twitching or myoclonus are likely to be missed, though one can be certain that all fits are recorded. Again, it is well recognized that persistent myoclonus is often the precursor of a fit, and patients who jerk habitually often receive some anticonvulsant medication which can effectively suppress both the jerking and the possibility of a fit. No allowance has been made for patients receiving regular anticonvulsants. Both these errors, however, would tend to mask the significance of the results, so that if, in spite of them, a general tendency shows, it is likely to be significant.

The duration of the epileptic activity may bo significant in relation to the prognosis, but it was? impossible to estimate this from the recordso available.

The patients themselves were a special group, selected for insulin treatment on the basis of favourable prognostic signs and symptoms, such as short duration of illness, floridity of symptoms, acute onset, etc. Moreover in a certain number of cases the diagnosis may have been problematic. These factors, however, do not affect the significance of epileptic phenomena in relation to prognosis.

A comparison was made between our results and the results of a three-year follow-up study of untreated schizophrenic patients discharged from the Maudsley Hospital in 1934 and 1935 (Guttmann, Mayer-Gross, and Slater, 1939). Guttmann and his colleagues used different categories in the classification of their results, but their " total recovery "group would seem to be comparable with the " recovered "group in the present investigation. We can therefore compare their figure of $21.5 \%$ recovered with the figure of $28.6 \%$ recovered in the present investigation. The results in the present series are biased, of course, since the patients were a selected group; also, in the present study the immediate outcome, not the three-year follow-up results, was used. Allowing for this bias, however, the difference is very small $(7 \cdot 1 \%)$.

We could not find any reports in the literature with which to compare our general findings on the 
relation of epileptic phenomena to prognosis. The significance of epileptic fits alone has from time to time been investigated, generally with inconclusive results, and in a recent statistical study Cohen (1951) found no correlation between shortterm prognosis and the occurrence of fits. It is therefore interesting that we could find a significant difference between the prognostic groups in relation to fits.

While it would appear from our findings that a patient who shows much epileptic activity during insulin treatment has a good prognosis, the relationship is not an absolute one ; not every patient who has such a high incidence is going to recover, nor is the opposite the case. In attempting to analyse exceptions, no constant factor was found that could be held generally responsible. Some of the " not recovered" patients with much epileptic activity had a history of head injury, some showed epileptic E.E.G.s before insulin therapy was started. Brain damage was not a frequent factor in these patients' histories, however, and had sometimes occurred in patients with little epileptic activity, some of whom had abnormal E.E.G.s. These findings appear contradictory, and in addition cannot be properly evaluated as only a minority had had electroencephalographic tests before treatment.

The age distribution for the different groups is shown in Table III, the average age in each group

TABLE III

THE AGE DISTRIBUTION OF THE PATIENTS

\begin{tabular}{lll|c|c|c|c|c|c}
\hline & & \multicolumn{5}{|c|}{ Age Range } \\
\cline { 2 - 7 } & & & -20 & $21-25$ & $26-30$ & $31-35$ & $36-40$ & $41-$ \\
\cline { 2 - 7 } $\begin{array}{l}\text { Recovered } \\
\text { Improved }\end{array}$ & $\cdots$ & $\ldots$ & $14^{*}$ & 26 & 22 & 13 & 9 & 3 \\
Not improved & $\ldots$ & 21 & 29 & 27 & 21 & 13 & 10 \\
\hline
\end{tabular}

*The figures represent the number of patients in a particular age range.

being roughly the same. Whereas in the "recovered" and "improved" groups the curves are approximately normal, in the "not improved" group the curve shows three peaks, one in the youngest and one in the oldest range, in addition to the one in the middle range. This might be expected, since it is known that the prognosis is worse for the young and the old than for the middle range.

One can consider myoclonic jerks, fits, etc. during insulin therapy as analogous to the " threshold " phenomena mentioned at the beginning of this paper. Assuming that those patients exhibiting epileptic phenomena under insulin were more easily excitable, i.e. would have a lower threshold, one would expect to find an inverse relation between the dose of insulin, on the one hand, and epileptic phenomena and prognosis on the other. As will be seen from Table IV, however, the average dosages of insulin were not significantly different in the three groups.

TABLE IV

AVERAGE NUMBER OF INSULIN UNITS GIVEN DAILY DURING TREATMENT

\begin{tabular}{c|c|c|c}
\hline \multirow{2}{*}{$\begin{array}{c}\text { Treatment } \\
\text { Year }\end{array}$} & \multicolumn{2}{|c|}{ Average No. of Insulin Units Daily } \\
\cline { 2 - 4 } & Recovered & Improved & Not Improved \\
\hline 1948 & 200 & 235 & 152 \\
1949 & 289 & 223 & 251 \\
1950 & 231 & 221 & 242 \\
\hline
\end{tabular}

The " threshold" may, of course, be related to blood sugar level rather than to insulin dosage. To infer directly the blood sugar level from the amount of insulin injected would generally be inadmissible, and particularly so in schizophrenic patients who are known to respond abnormally to insulin and who are often found to be "insulin resistant".

Finally it is possible that the short-term result of treatment depends on the depth of the metabolic change induced by insulin, and that the epileptic phenomena are simply an indicator of the degree of such a change. The aim during treatment is to reach coma level, and a certain safe depth is produced in each patient. It can be assumed that the metabolic change is similar in each patient. It can be assumed that the metabolic change is similar in all cases where coma is reached. Since there was no significant difference between the groups in the average number of comas per patient, the average dose of insulin per patient, or the depth of coma aimed at, we may assume that the metabolic change in the subjects in each group was similar in degree.

\section{Conclusions}

The most obvious explanation of these findings would be that the therapeutic effect of deep insulin treatment is due to the production of these epileptic phenomena. There is enough evidence from other fields of the direct therapeutic action of induced epileptic phenomena to suggest such a view.

There is, however, another possibility. When the insulin treatment results are compared with the spontaneous recovery rate in an untreated group of schizophrenics it has been shown that the two groups are not very different. The comparison to be exact would of course require a more detailed analysis than we were able to carry out, but even 
although the conclusion must be regarded as approximate only, it would seem that the more frequent appearance of epileptic phenomena after the administration of insulin is simply a characteristic of the group who recover.

A further theory which might help to explain our findings is Hill's $(1948,1950)$ suggestion that the relation between the epileptic threshold and the schizophrenic state is a changeable one, and is not constant in one patient at all times or at different stages of his illness. There is a dynamic interplay between the tendency to induced epileptic phenomena on the one hand and the stage of the illness on the other, so that the threshold falls as the illness nears its end. Hill suggests that this changing threshold is evidence of the functioning of a homeostatic mechanism, which brings about a restitution of the "normal balance" of the central nervous system.

More evidence has appeared than that quoted by Hill to support such a view. Corriol and Bert (1950) have shown the changes in the metrazolflicker threshold in the course of a catatonic illness. We also intend to report a similar investigation elsewhere. It is therefore possible that the lowered threshold of the "recovered "group is due to the illness being already near its end when insulin therapy was started. If this is so, then it might be possible to regard a low insulin, or possibly metrazol-flicker, threshold as a sign of a good short-term prognosis in schizophrenia, and to elaborate the insulin threshold or some similar procedure into a short-term prognostic test.

\section{Summary}

The case records of 304 schizophrenic patients, who received deep insulin therapy, have been examined.

A method was evolved to assess indirectly and approximately the amount of epileptic activity during coma therapy. This consisted in counting the days on which epileptic phenomena occurred during treatment and expressing them in percentages of the total number of treatment days.

The average of these figures is significantly higher in the group of patients who recovered than in those who did not.

An explanation of these findings is offered.

We wish to thank Dr. D. Hill for his help and encouragement. Mr. A. S. C. Ehrenberg gave advice on statistical problems.

\section{REFERENCES}

Cohen, M. (195)1. Arch. Neurol. Psychiat., Chicago, 66, 412.

Corriol, J., and Bert, J. (1950). Ann. méd.-psychol., 108 (I), 588

Davis, P. A. (1940). Amer. J. Psychiat., 96, 851.

Gastaut, H., and Hunter, J. (1950). Electroenceph. clin. Neurophysiol., 2, 263. Gibbs, F. A., Gibbs, E. L., and Lennox, W. G. (1938). Amer. J.

Guttmann, E., Mayer-Gross, W., and Slater, E. T. O. (1939). Journal of Neurology, Neurosurgery and Psychiatry, n.s. 2, 25.

Hill, D. (1948). Folia psychiat., Amst. 51, 95.

(1950). Congrès internationale de Psychiatrie, Paris 1950

Hoch, P. H. (1943). Amer. J. Psychiat., 99, 507.

Jasper, H. H., Fitzpatrick, C. P., and Solomon, P. (1939). Ibid.(ד) $95,835$.

Kraepelin, E. (1910). Psychiatrie, 8th ed., vol. 2. Barth, Leipzig. Krapf, E. (1929). Arch. Psychiat. Nervenkr. 83, 547.

Leiberman, D. M., and Hoenig, J. (1953). E.E.G. Investigations in Recurrent Catatonia. (In the press)

,$- \frac{\text { Recurrent Catatonia. (1n the press). }}{-}$, and Hacker, H. (1953). The Cardiazol Flicker Threshold in 104 Neuropsychiatric Patients. Electroenceph. clin. Neurophysiol. (In the qress.) Neurophysiol. (In the qress.)
Meduna, L. (1937). Die Konvulsionstherapie der Schizophrenie.
Marhold, Halle.

Müller, G. (1930). Allg. Z. Psychiat., 93, 235. 